\title{
Erratum to: The relationship between dorsolateral prefrontal activation and speech performance-based social anxiety using functional near infrared spectroscopy
}

\author{
Lisa H. Glassman 1,2,3 • Anootnara T. Kuster ${ }^{4}$. Jena A. Shaw ${ }^{3}$ - Evan M. Forman ${ }^{3}$.
}

Meltem Izzetoglu $^{3} \cdot$ Alyssa Matteucci $^{3} \cdot$ James D. Herbert $^{3}$

Published online: 10 June 2017

(C) Springer Science+Business Media, LLC 2017

Erratum to: Brain Imaging and Behavior

\section{DOI 10.1007/s11682-016-9554-1}

The authors would like to add an acknowledgment below:

Acknowledgements Data presented in this manuscript were collected as part of the second author's doctoral dissertation.

The online version of the original article can be found at http://dx.doi.org/ 10.1007/s11682-016-9554-1

Lisa H. Glassman

LHG28@drexel.edu

1 Center for Excellence in Stress and Mental Health, VA San Diego, San Diego, CA, USA

2 University of California, San Diego, San Diego, CA, USA

3 Department of Psychology, Drexel University, Stratton Hall, 3141

Chestnut St, Philadelphia, PA 19104, USA

4 Khon Kaen University, Khon Kaen, Thailand 